\title{
Genetic Risk Factors of Systemic Lupus Erythematosus in the Malaysian Population: A Minireview
}

\author{
Hwa Chia Chai, ${ }^{1}$ Maude Elvira Phipps, ${ }^{1}$ and Kek Heng Chua ${ }^{2}$ \\ ${ }^{1}$ Jeffrey Cheah School of Medicine and Health Sciences, Monash University, Sunway Campus, 46150 Selangor Darul Ehsan, Malaysia \\ ${ }^{2}$ Department of Molecular Medicine, Faculty of Medicine, University of Malaya, 50603 Kuala Lumpur, Malaysia
}

Correspondence should be addressed to Kek Heng Chua, khchua@um.edu.my

Received 27 April 2011; Accepted 20 July 2011

Academic Editor: Sara Marsal

Copyright ( $) 2012$ Hwa Chia Chai et al. This is an open access article distributed under the Creative Commons Attribution License, which permits unrestricted use, distribution, and reproduction in any medium, provided the original work is properly cited.

\begin{abstract}
SLE is an autoimmune disease that is not uncommon in Malaysia. In contrast to Malays and Indians, the Chinese seem to be most affected. SLE is characterized by deficiency of body's immune response that leads to production of autoantibodies and failure of immune complex clearance. This minireview attempts to summarize the association of several candidate genes with risk for SLE in the Malaysian population and discuss the genetic heterogeneity that exists locally in Asians and in comparison with SLE in Caucasians. Several groups of researchers have been actively investigating genes that are associated with SLE susceptibility in the Malaysian population by screening possible reported candidate genes across the SLE patients and healthy controls. These candidate genes include $M H C$ genes and genes encoding complement components, TNF, Fc $\gamma$ R, T-cell receptors, and interleukins. However, most of the polymorphisms investigated in these genes did not show significant associations with susceptibility to SLE in the Malaysian scenario, except for those occurring in $M H C$ genes and genes coding for TNF- $\alpha$, IL-1 $\beta$, IL-1RN, and IL- 6 .
\end{abstract}

\section{Introduction}

Systemic lupus erythematosus (SLE) is the prototypical autoimmune disease that is characterized by autoantibody production, complement activation, and immune complex deposition leading to diverse clinical manifestations and target tissue damage. The prevalence of SLE is estimated to be between 40 and 400 cases per 100,000 individuals [1]. While the precise etiology of SLE still remains vague, genetic predisposition and environmental and hormonal factors are deemed to play important roles in its pathogenesis. Severity, acquisition risk, and clinical manifestations of this disease can vary by ethnicity, geography, and sex, with a prevalence that is higher in women during their childbearing ages and some non-European populations such as African Americans, Hispanics, and Asians [2, 3].

In Asians, the prevalence of SLE generally falls within $30-50 / 100,000$ individuals. SLE is more frequent among Chinese communities in Asia than it is in India and tropical Africa [4]. Malaysia is a multiracial country. In the peninsular, the Malays (55.1\%), Chinese $(24.3 \%)$, and Indians $(7.4 \%)$ represent the largest ethnic groups. A prevalence of
43/100,000 individuals in Malaysia has been reported [5, 6]. Likewise, Chinese have the highest prevalence of SLE in Malaysia $(57 / 100,000)$, followed by Malays $(33 / 100,000)$ and Indians $(14 / 100,000)[7,8]$. The overall 5-year and 10-year survival rates were reported as $82 \%$ and $70 \%$, respectively [5], whereas the overall mortality rate was $20.2 \%$ [9]. Renal involvement is highest among the Malaysian patients [5]. However, the major cause of death in Malaysian SLE patients was reported to be from infection [9].

Pathogenesis of SLE is associated with functional deficiency of multiple immunologic components, including the innate immune system, altered immune tolerance mechanisms, hyperactivation of $\mathrm{T}$ and $\mathrm{B}$ cells, reduced ability of immune complexes and apoptotic cell clearance, and defects in multiple immune regulatory networks [10]. The failure of these mechanisms could be due to the influence of variants within SLE susceptibility genes. To date, many different genes have been found to contribute to disease susceptibility. In a small proportion of patients $(<5 \%)$, a single gene could become the key player for this disease [11]; however, multiple genes have been implicated in most patients. It is estimated that at least four susceptibility 
genes or loci are needed for the development of the disease [12]. The susceptibility genes most extensively studied are within the major histocompatibility complex (MHC). It is believed that human leukocyte antigen (HLA) class II gene variants are very important. The introduction of genomewide association studies (GWASs) has not only helped us to support the findings from previous candidate gene studies, but also unveiled many other novel genetic loci that may be important. Candidate genes that have been recently discovered can be clustered into three main groups: (i) IRF5, STAT4, TNFAIP3, and TREX1 which are involved in innate immune response including TLR/interferon signalling pathway; (ii) $H L A-D R, P T P N 22, P D C D 1, L Y N, B L K$, and BANK1 which are involved in immune signal transduction of $\mathrm{B}, \mathrm{T}$, and antigen-presenting cells; (iii) C2, C4, FCGRs, CRP, and ITGAM which are involved in immune complex clearance mechanism $[13,14]$.

The genetic information obtained from GWAS has allowed many researchers to investigate specific variants for particular genetic loci using a variety of approaches such as RFLPPCR, tetra-primer ARMS-PCR, and real-time genotyping PCR. This in turn has enabled the replication of these experiments and confirmed those associated polymorphisms with SLE in different populations. Genetic heterogeneity is common among populations in SLE, especially between Caucasians and Asians. For instance, PTPN22, which demonstrated significant association with SLE in Caucasians, was not found to be associated with some ethnicities in Asia [15]. The identification of genetic heterogeneity may enhance our understanding of mechanisms that lead to SLE pathogenesis in certain populations and subsequently may permit more precise diagnosis, prognosis, and treatment for the patients.

In Malaysia, researchers have been actively looking into the genetic risk factors of SLE in the multiracial population for the past 15 years. These efforts have generated a considerable amount of data that have been useful contributions to enriching global statistics and knowledge of SLE. PCR-based methods were mainly used in these studies. In this paper, the association of several candidate susceptibility genes with SLE in Malaysian population will be discussed and summarized (Table 1). In addition, genetic heterogeneity in SLE susceptibility observed in different ethnicities will be discussed.

\section{Candidate Genes}

2.1. Major Histocompatibility Complex Genes. The major histocompatibility complex (MHC), which contains human leukocyte antigen (HLA) genes, is a large genomic region located on chromosome 6. HLA antigens and genes have long been associated with SLE, and this can be dated back to 1971, when Grumet et al. [33] reported a possible relationship. Of the several classes of HLA, HLA class II genes seem particularly important in SLE. They encode cellsurface antigen-presenting proteins that present antigens to $\mathrm{T}$ cells and in turn stimulate the multiplication of Thelper cells and production of antibodies by B cells. HLA class II genes have also been associated with the presence of certain autoantibodies such as anti-Sm, anti-Ro, antiLa, anti-nRNP, and anti-DNA antibodies, which have been useful biomarkers in SLE diagnosis. HLA-DR2 has been reported to be consistently associated with SLE in both Caucasian and Asian populations [34, 35]. HLA class III genes, particularly those encoding complement components $\mathrm{C} 2$ and C4, may also confer increased risk for SLE in different ethnicities

In Malaysia, Azizah et al. [16] reported significant association of HLA-DR2, -DQB $1 * 0501$, and -DQB1 $* 0601$ with SLE in Malays. A significant positive association of DR2 and DQB1 $* 0501$ with renal involvement and DR8 with alopecia in Malays was also described in their study. For the investigation of the role of HLA genes in autoantibody expression, they found significant association of DQB $1 * 0601$ with antiSm/RNP, DR2 with anti-Ro/La, and DR2, DRB1 $* 0501$ and $* 0601$ with anti-dsDNA. The same group of researchers also carried out similar study on Chinese population and suggested that $\mathrm{DQB} 1 * 0102, \mathrm{DQB} 1 * 0501, * 0601$, and $\mathrm{DPB} 1 * 0901$ were significantly associated with SLE [17]. Clinically, a strong association of DR2 and DQA $1 * 0301$ with renal involvement and $\mathrm{DQA} 1 * 0102$ with alopecia was reported. In contrast to Malays, DQA $1 * 0102$ and DQA $1 * 0301$ were observed to be strongly associated with anti-Ro/La and anti-dsDNA, respectively, in Chinese. Earlier on, Doherty et al. [18] reported that HLA-DRw15 and DQw1 were observed to be significantly associated with SLE among Southern Chinese in Malaysia and most prevalent in patients with lupus nephritis and cutaneous manifestation.

A recent comprehensive study conducted by Mohd-Yusuf and coworkers [19] in Malaysia revealed that HLA A $* 1101$, 1102, DRB5*01-02, DQB1 $* 05, \mathrm{DRB} 3 * 0101,0201,0202$, 0203,0301 , and DQB1 $* 0301,0304$ were significantly associated with SLE in Malaysians. In addition, DRB $1 * 0701$ and DRB4 $* 0101101,0102,0103$ alleles were significantly increased in the Malay SLE patients, whilst DRB1*16011606 (DR2 subtype) and DRB5 $* 0101,0102,0201,0202$, 0203 alleles were significantly higher in Chinese SLE patients. The investigation revealed that these two different sets of DR alleles may be specific and representative for the two ethnic groups in this SLE cohort and that DQB $1 * 05$ could be the common HLA susceptibility allele in the Malaysian SLE population.

2.2. Complement Components. The complement system is mainly involved in innate immunity, whereby it helps to remove cellular debris from foreign and apoptotic cells. The links between complement system activity with SLE have been reported since the 1980s. Mutant C4 genes have been mostly reported in Caucasian families, but are still uncommon in other populations. Apart from Caucasians, the presence of $\mathrm{C} 4 \mathrm{~A}$ null allele $(\mathrm{C} 4 \mathrm{aQ} 0)$ was also observed in Chinese and Japanese with SLE by Dunckley et al. [36]. In the Malaysian scenario, none of the mutations located at exons 13, 20 and 29 of $\mathrm{C} 4$ gene, as well as the null alleles, was found to be significantly associated with SLE [20]. The same situation was also observed in Malaysian Southern Chinese by Doherty et al. [18]. However, a synergistic effect 


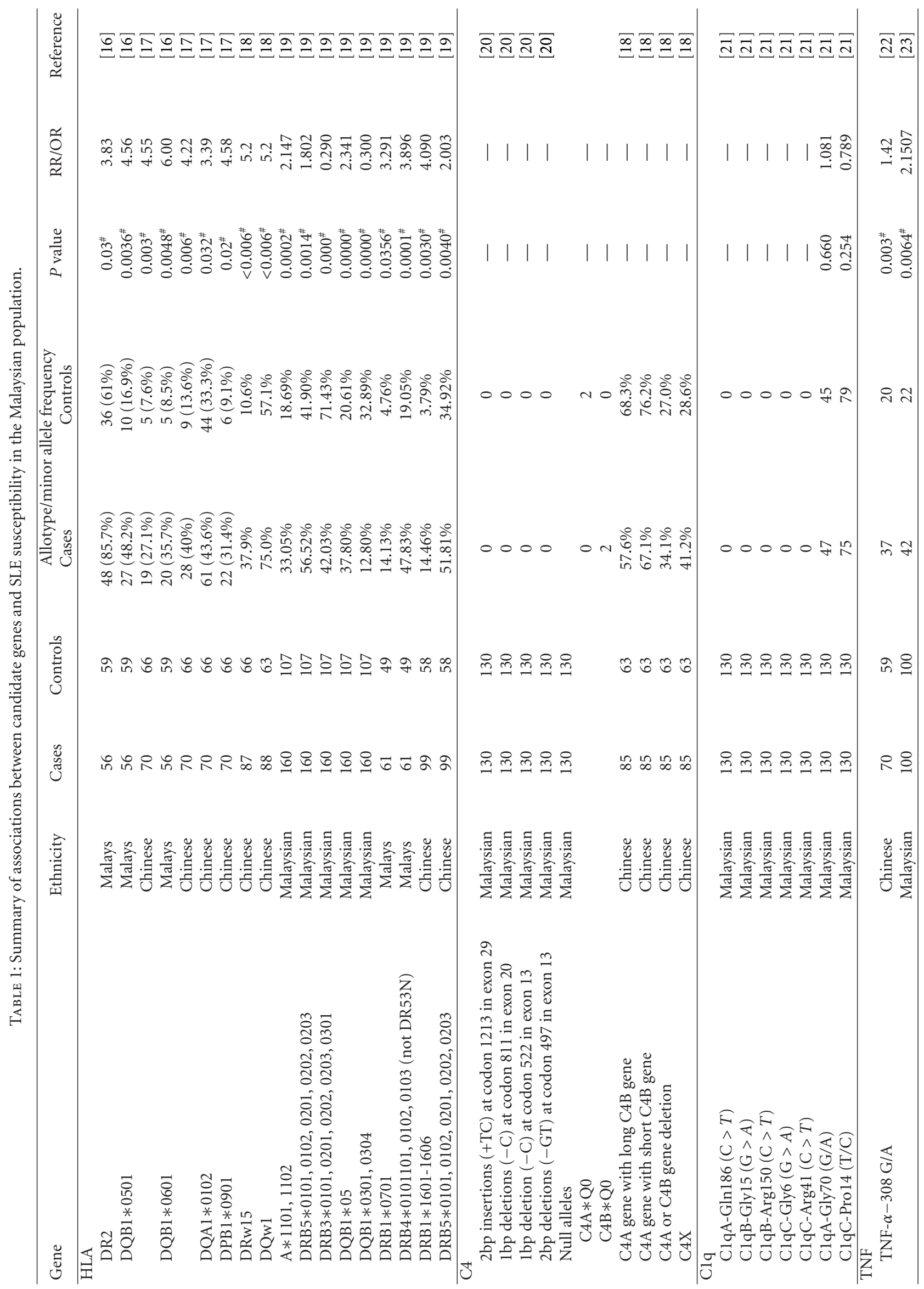




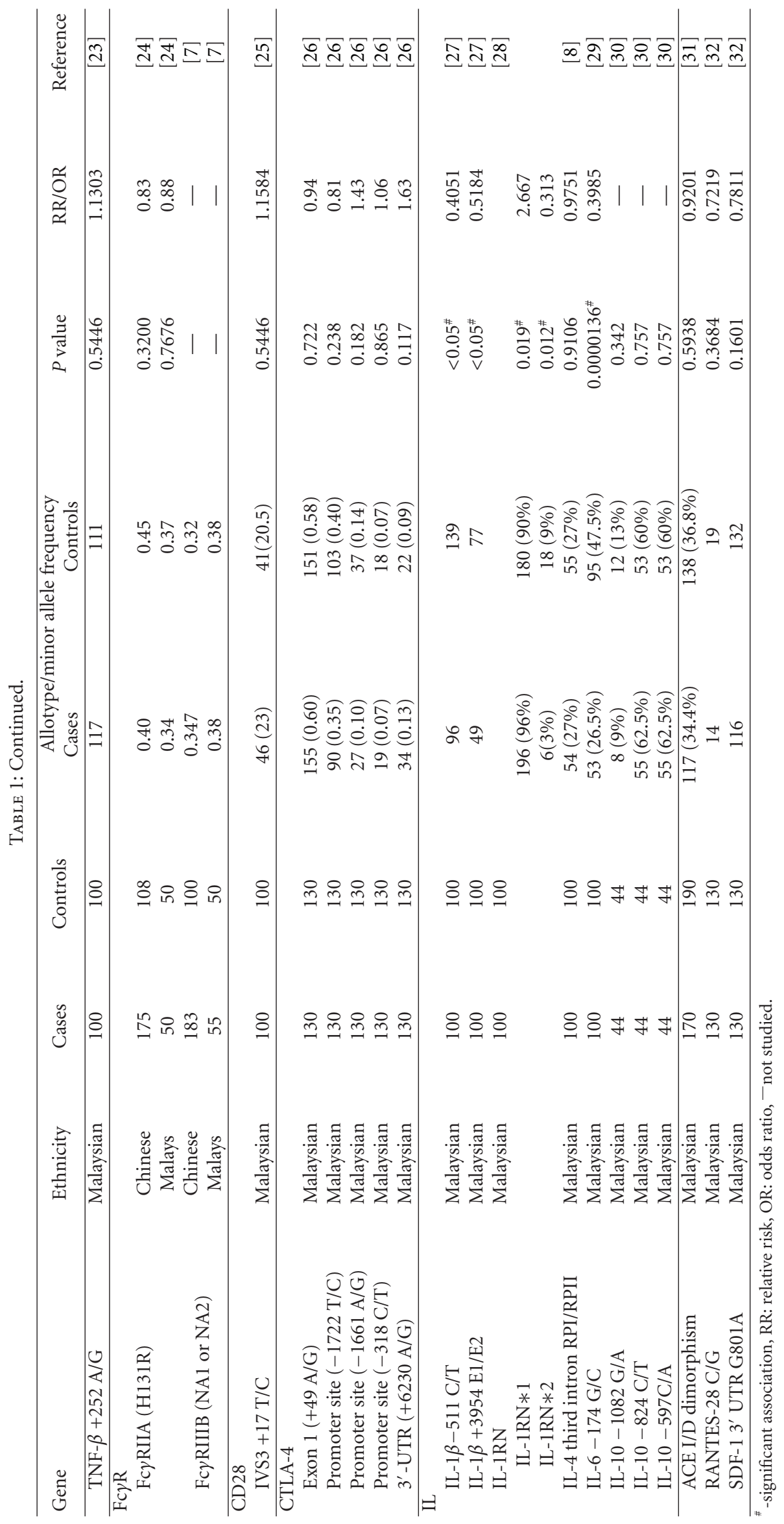


of C4 deletions and HLA-DRw15 in conferring disease susceptibility was detected.

The other complement component of particular importance in SLE is C1q. Individuals having a congenital genetic deficiency of C1q gene could develop SLE-like symptoms at more than $90 \%$ prevalence $[37,38]$. Various mutations in Clq have been reported, including nonsense mutations, missense mutations and single nucleotide polymorphisms (SNP). It is conceivable that these may lead to failures in the synthesis of intact $\mathrm{Clq}$ molecules leading to abnormal immune responses. While C1q deficiency was reported to be associated with SLE in Turkish and Mexican subjects [39, 40], no association was observed between any of the mutations [at C1qA-Gln186 (C > T), C1qB-Gly15 (G > A), C1qB-Arg150 $(\mathrm{C}>\mathrm{T})$, C1qCGly6, $(\mathrm{G}>\mathrm{A})$, and C1qC-Arg41 $(\mathrm{C}>\mathrm{T})$ ], or SNPs [at C1qAGly70 (G/A), and C1qC-Pro14 (T/C)] within $\mathrm{C} 1 \mathrm{q}$ and SLE in the Malaysia [21].

2.3. Tumour Necrosis Factor. Tumour necrosis factor (TNF) genes are situated at the short arm of chromosome 6 . TNF proteins are a group of low-molecular-weight cytokines that mediate inflammation processes. TNF-alpha (TNF- $\alpha$ ) protein, also known as cachectin, has been frequently investigated. It plays an important role in the regulation of immune cells, stimulation of apoptotic cell death, and induction of inflammation. Cytokine imbalances are believed to be drivers of certain autoimmune diseases, including SLE. The first biallelic TNF- $\alpha$ gene polymorphism was reported by Wilson et al. [41], which involved a single base change from $G$ to $A$ at the position -308 in the promoter region of the gene. A metaanalysis study revealed that the $308-\mathrm{A} / \mathrm{G}$ functional promoter polymorphism association was inconsistent. However the risk genotype $\mathrm{A} / \mathrm{A}$ and risk allele $\mathrm{A}$ were associated with SLE in European populations but not in Asian or African populations [42]. The other member of TNF family is TNFbeta (TNF- $\beta$ ), known as lymphotoxin. The biallelic polymorphism in intron 1 of TNF- $\beta$ gene is believed to influence TNF- $\alpha$ production and has been associated with SLE in both Caucasian and Asian populations [43-45].

Risk allele A of TNF- $\alpha-308$ was associated with SLE in Malaysian cohorts as reported by Azizah et al. [22] and Chua et al. [23], in conjunction with a significant increased frequency of $\mathrm{A} / \mathrm{G}$ heterozygotes in patients. The TNF- $\beta$ +252 polymorphism in intron 1 did not feature in SLE susceptibility [23].

2.4. Fc Gamma Receptors. Fc gamma receptors (Fc $\gamma$ Rs) are present on the surface of most effector cells of the immune system and involved in mediation of phagocytosis, immune complex clearance, antibody-dependent cell-mediated cytotoxicity and stimulation of inflammatory cells [46].

Fc $\gamma$ RIIa is the most widely distributed member of $\mathrm{Fc} \gamma \mathrm{R}$, and FcyRIIA gene may occur in two allelic forms that can cause single amino acid residue modification at position 131. Fc $\gamma$ RIIa-R131 has a relatively lower affinity for human IgG2 that causes less ability to process and clear immune complexes effectively. Thus it was suggested as a disease susceptibility factor for SLE, as observed in a meta-analysis that involved European, African, and Asian populations [47]. However many studies actually did not show association between polymorphism of Fc $\gamma$ RIIA and SLE susceptibility in their populations [48], including Malays and Chinese in Malaysia [24].

Fc $\gamma$ RIII is encoded by two distinct but highly homologous genes: FcyRIIIA and FcyRIIIB. A SNP (T to G substitution) in FcyRIIIA that results in a valine (V) substitution for phenylalanine $(\mathrm{F})$ at amino acid residue position 158 has been correlated with SLE in Asians [35]. As for Fc $\gamma$ RIIIB, the polymorphism may occur as neutrophil antigen 1 (NA1) or 2 (NA2). Study by Yap and coworkers [7] showed no association between Fc $\gamma$ RIIIB-NA polymorphism and SLE in Malay and Chinese patients in Malaysia. This was in agreement with other reports in Caucasian SLE patients. They were also able to detect a Chinese SLE patient with NAnull, which is a consequence of a Fc $\gamma$ RIIIB gene deficiency or deletion.

2.5. T-Cell Receptors. CD28 and CTLA-4 are receptors on Tcell surfaces that have opposite effects on T cells. CD28 is a costimulatory molecule which is responsible for T-cell proliferation, cytokine production, and the prevention of T-cell anergy [49], whereas CTLA-4 maintains the immune response at physiological level by regulating the activity of CD28 and T-cell activation.

Few studies have been carried out to investigate the association of CD28 gene polymorphism with SLE susceptibility. A study performed on the Malaysian population demonstrated no association between CD28 IVS3 + 17T/C SNP and SLE susceptibility, although the frequency of $\mathrm{T}$ allele and its corresponding homozygous was the highest among the population [25]. In contrast to CD28, there have been more reports of the association of CTLA- 4 polymorphisms with SLE, both in Caucasians and Asians. CTLA-4 promoter $(-1722 \mathrm{~T} / \mathrm{C})$ polymorphism and $(+49 \mathrm{~A} / \mathrm{G})$ polymorphism from exon-1 were found to have their TC and GG genotypes, respectively, being significantly associated with SLE in Asian populations $[35,50]$. However, polymorphisms in CTLA4 gene $(+49 \mathrm{~A} / \mathrm{G}$ at exon $1,-1722 \mathrm{~T} / \mathrm{C},-1661 \mathrm{~A} / \mathrm{G}$ and $-318 \mathrm{C} / \mathrm{T}$ at promoter sites and $+6230 \mathrm{~A} / \mathrm{G}$ in $3^{\prime}$-untranslated region) were not reported to be important in Malaysian SLE patients [26].

2.6. Interleukins. Interleukins are a group of cytokines, the majority of which are secreted by helper T cells, monocytes, macrophages, dendritic cells, natural killer cells, and B cells. They are mainly involved in promoting the development and differentiation of $\mathrm{T}$ and $\mathrm{B}$ cells and activation of natural killer cells.

Interleukin-1 (IL-1) is a polypeptide encompassing IL-1 alpha (IL- $1 \alpha$ ) and IL- 1 beta (IL- $1 \beta)$. IL-1 gene is located on chromosome 2 , and genes encoding IL- $1 \alpha$ and IL- $1 \beta$ are in close proximity to each other. The defective production of IL1 has been implicated in development of SLE since 1983 [51]. However, not many studies have been conducted to investigate the association between $I L-1$ gene polymorphisms and susceptibility to SLE. According to Chua et al. [27], SLE 
patients in Malaysia are susceptible to IL- $1 \beta-511 \mathrm{C} / \mathrm{T}$ polymorphism, with the $\mathrm{C}$ allele and its corresponding homozygous exhibiting a higher risk to SLE. These findings differed from a report by Parks et al. [52] that showed T allele had more potential to confer risk of SLE in African Americans. In Taiwan, no association between IL-1 $\beta-511$ C/T polymorphism and SLE was observed [53]. In a similar study carried out by Chua and coworkers [27], a significant correlation of another IL-1 $\beta$ polymorphism $(+3954$ E1/E2 in exon 5) with SLE susceptibility in Malaysian population was noted, with E1 allele rather than the E2 at higher frequency among patients. This was also the case in Columbian SLE patients but not in the Taiwanese [53, 54].

The secretion and activity of IL-1 are tightly counterbalanced by IL-receptor antagonist (IL-1ra), which competitively binds to the same receptor as IL-1. IL-1RN gene, which encodes IL-1ra, is also situated on chromosome 2 . The dysregulation of IL-1 production by IL-1ra will cause abnormal inflammatory activity that leads to subsequent tissue damage, which is the characteristic pathogenesis of SLE. In as much as IL-1ra may contribute to the occurrence of SLE, many studies have been done to investigate the association of polymorphisms in $I L-1 R N$ gene with SLE susceptibility. Polymorphism in IL-1ra is always characterised by variable numbers of an 86-bp tandem repeat in the intron 2 that may functionally affect three potential protein binding sites: an $\alpha$ interferon silencer $\mathrm{A}$, a $\beta$-interferon silencer $\mathrm{B}$, and an acutephase response element [55]. The first study to correlate this polymorphism with SLE susceptibility was done on Caucasians in 1994, and carriage of IL-1RN $* 2$ was reported to be associated with severity rather than susceptibility to SLE [56]. In Malaysia, however, the risk allele associated with SLE susceptibility in SLE patients was IL-1RN $* 1$ instead. The IL$1 \mathrm{RN} * 2$ allele displayed an inverse association [28].

Interleukin-4 (IL-4) is secreted by T-helper type-2 cells and responsible for proliferation and differentiation of $\mathrm{B}$ and $\mathrm{T}$ cells, as well as production of antibodies. IL-4 gene is located on human chromosome 5 , and the study of the impact of its polymorphisms on SLE susceptibility is not as popular as other candidate genes. An IL4 haplotype -590C/ $-33 \mathrm{C} / 9241 \mathrm{G} / 14965 \mathrm{C}$ was significantly associated with SLE in Taiwan Chinese population [57]. Another study in Taiwan revealed the association of IL-4 -590T/C and intron 3 VNTR (variable number of tandem repeats) poly-morphisms with the presence of certain clinical manifestations in SLE patients [58]. In the Malaysian cohort that was studied, the VNTR variants within intron 3 of $I L-4$ gene were not associated with SLE susceptibility [8].

Interleukin-6 (IL-6) gene, located on chromosome 7, is another interleukin gene of interest that has been studied and associated with the susceptibility of SLE. IL- 6 promoter polymorphism $(-174 \mathrm{G} / \mathrm{C})$ is commonly investigated as a risk factor in SLE. While a study on Malaysian population found a significant correlation between homozygous $\mathrm{G}$ genotype and SLE susceptibility, none of the studies in Taiwan, Iran, and Portugal reported the association of this polymorphism with SLE in their populations $[29,59-61]$.

Interleukin-10 is also believed to play an important role in the pathogenesis of SLE. Various polymorphisms in IL-10 promoter region have been reported to display significant association with SLE susceptibility [62-64]. An earlier study reported that the IL10.G microsatellite alleles in IL-10 promoter region had significantly higher frequency in Caucasian SLE patients [64]. A study investigating the relationship of three SNPs in $I L-10$ gene promoter $(-1082 \mathrm{G}>\mathrm{A},-824 \mathrm{C}>$ $\mathrm{T}$, and $-597 \mathrm{C}>\mathrm{A}$ ) with SLE susceptibility in Malaysian population revealed that haplotype frequencies rather than genotypes or alleles were more important [30].

2.7. Other Genes. The role of angiogenic-converting enzyme $(A C E)$ gene I/D dimorphism in susceptibility to SLE in the Malaysian population was illustrated by Lian and coworkers [31]. ACE gene, located on the $\mathrm{q}$ arm of chromosome 17 , produces protein which is an important player in the renin-angiotensin system and kallikrein-kininogen system [65]. Dysregulation of ACE could lead to vascular damage, particularly in kidneys of SLE patients. In that study, no significant difference was observed in the distribution of I and $\mathrm{D}$ alleles between cases and healthy controls although ID heterozygote did show significant association with SLE [31]. This finding was in accordance with what was reported in African-American and European-American populations [66] but contradicted those in Japanese and Slovakian populations, whereby I and D alleles were found, to be significantly associated with SLE, respectively $[66,67]$.

Polymorphisms at position 28 of the regulated on activation, normal $\mathrm{T}$ cell expressed and secreted (RANTES) gene promoter region and position 801 in $3^{\prime}$ UTR of stromal cellderived factor 1 (SDF-1) gene were also analysed by Lian et al. [32]. Again, both polymorphisms did not show significant association with SLE in Malaysia and similar observations were also reported in Mexican and Han Chinese populations [68-70].

\section{Conclusion}

Most studies conducted in Malaysian SLE patients did not exhibit significant association of the candidate genes with susceptibility, safe for a few which are within the human MHC. There are several pertinent reasons for these findings. Firstly, this could be due to smaller sample sizes as it is often difficult to obtain large numbers of SLE patients within a medical centre or hospital within a relatively short period of time when such studies are undertaken. So far, there has yet to be a long term or longitudinal national study on this enigmatic disease. The second reason may be that given the complexity of SLE and the dynamic nature of the disease, there may well be different sets of genes and biological players that assume various roles during the precipitation and pathogenesis of SLE from predisposition to actual onset and resultant progression. The genetic heterogeneity evident in different SLE patients of various ethnicities could also be attributed to the inheritance of different ancestral genotypes that impact upon the development and/or progression of this disease [13]. Gene-gene and gene-environment interactions could also confer differences in susceptibility to or be protective against a particular disease in different 
populations or ethnic groups. It is hoped that with larger and better defined patient sets and appropriate controls, more comprehensive genetics and systems biology approaches, and better technologies, we will be able to gain a better understanding of SLE and insight into ways of managing this most enigmatic and challenging of autoimmune diseases.

\section{References}

[1] C. G. Helmick, D. T. Felson, R. C. Lawrence et al., "Estimates of the prevalence of arthritis and other rheumatic conditions in the United States. Part I," Arthritis and Rheumatism, vol. 58, no. 1, pp. 15-25, 2008.

[2] C. S. Lau, G. Yin, and M. Y. Mok, "Ethnic and geographical differences in systemic lupus erythematosus: an overview," Lupus, vol. 15, no. 11, pp. 713-714, 2006.

[3] R. Voskuhl, "Sex differences in autoimmune disease," Biology of Sex Differences, vol. 2, no. 1, p. 1, 2011.

[4] A. O. Frank, "Apparent predisposition to systemic lupus erythematosus in Chinese patients in West Malaysia," Annals of the Rheumatic Diseases, vol. 39, no. 3, pp. 266-269, 1980.

[5] F. Wang, C. L. Wang, C. T. Tan, and M. Manivasagar, "Systemic lupus erythematosus in Malaysia: a study of 539 patients and comparison of prevalence and disease expression in different racial and gender groups," Lupus, vol. 6, no. 3, pp. 248-253, 1997.

[6] E. Osio-Salido and H. Manapat-Reyes, "Epidemiology of systemic lupus erythematosus in Asia," Lupus, vol. 19, no. 12, pp. 1365-1373, 2010.

[7] S. N. Yap, M. E. Phipps, M. Manivasagar, S. Y. Tan, and J. J. Bosco, "Fc gamma receptor IIIB-NA gene frequencies in patients with systemic lupus erythematosus and healthy individuals of Malay and Chinese ethnicity," Immunology Letters, vol. 68, no. 2-3, pp. 295-300, 1999.

[8] K. H. Chua, B. P. Kee, S. Y. Tan, and L. H. Lian, "Genetic polymorphisms of interleukin-4 third intron region in the Malaysian patients with systemic lupus erythematosus," Journal of Medical Sciences, vol. 8, no. 4, pp. 437-442, 2008.

[9] S. S. Yeap, S. K. Chow, M. Manivasagar, K. Veerapen, and F. Wang, "Mortality patterns in Malaysian systemic lupus erythematosus patients," Medical Journal of Malaysia, vol. 56, no. 3, pp. 308-312, 2001.

[10] G. S. Firestein, Kelley's Textbook of Rheumatology, W. B. Saunders, Philadelphia, Pa, USA, 2008.

[11] C. C. Mok and C. S. Lau, "Pathogenesis of systemic lupus erythematosus," Journal of Clinical Pathology, vol. 56, no. 7, pp. 481-490, 2003.

[12] P. H. Schur, "Genetics of systemic lupus erythematosus," Lupus, vol. 4, no. 6, pp. 425-437, 1995.

[13] H. S. Lee and S. C. Bae, "What can we learn from genetic studies of systemic lupus erythematosus? Implications of genetic heterogeneity among populations in SLE," Lupus, vol. 19, no. 12, pp. 1452-1459, 2010.

[14] I. T. W. Harley, K. M. Kaufman, C. D. Langefeld, J. B. Harley, and J. A. Kelly, "Genetic susceptibility to SLE: new insights from fine mapping and genome-wide association studies," Nature Reviews Genetics, vol. 10, no. 5, pp. 285-290, 2009.

[15] Y. Kochi, A. Suzuki, R. Yamada, and A. Yamamoto, "Genetics of rheumatoid arthritis: underlying evidence of ethnic differences," Journal of Autoimmunity, vol. 32, no. 3-4, pp. 158-162, 2009.

[16] M. R. Azizah, S. S. Ainol, N. C. Kong, Y. Normaznah, and M. N. Rahim, "HLA antigens in Malay patients with systemic lupus erythematosus: association with clinical and autoantibody expression," The Korean Journal of Internal Medicine, vol. 16, no. 2, pp. 123-131, 2001.

[17] M. R. Azizah, S. S. Ainol, S. H. Kuak, N. C. T. Kong, Y. Normaznah, and M. N. Rahim, "The association of the HLA class II antigens with clinical and autoantibody expression in Malaysian Chinese patients with systemic lupus erythematosus," Asian Pacific Journal of Allergy and Immunology, vol. 19, no. 2, pp. 93-100, 2001.

[18] D. G. Doherty, R. Ireland, A. G. Demaine et al., "Major histocompatibility complex genes and susceptibility to systemic lupus erythematosus in Southern Chinese," Arthritis and Rheumatism, vol. 35, no. 6, pp. 641-646, 1992.

[19] Y. Mohd-Yusuf, M. E. Phipps, S. K. Chow, and S. S. Yeap, "HLA-A*11 and novel associations in Malays and Chinese with systemic lupus erythematosus," Immunology Letters, vol. 139, no. 1-2, pp. 68-72, 2011.

[20] S. M. Puah, L. H. Lian, C. H. Chew, K. H. Chua, and S. Y. Tan, "A study of association of the complement C4 mutations with systemic lupus erythematosus in the Malaysian population," Lupus, vol. 16, no. 9, pp. 750-754, 2007.

[21] C. H. Chew, K. H. Chua, L. H. Lian, S. M. Puah, and S. Y. Tan, "PCR-RFLP genotyping of C1q mutations and single nucleotide polymorphisms in Malaysian patients with systemic lupus erythematosus," Human Biology, vol. 80, no. 1, pp. 83-93, 2008.

[22] M. R. Azizah, S. H. Kuak, S. S. Ainol, M. N. Rahim, Y. Normaznah, and K. Norella, "Association of the tumor necrosis factor alpha gene polymorphism with susceptibility and clinicalimmunological findings of systemic lupus erythematosus," Asian Pacific Journal of Allergy and Immunology, vol. 22, no. 2-3, pp. 159-163, 2004.

[23] K. H. Chua, T. P. Lau, C. T. Foo, S. Y. Tan, and L. H. Lian, "Genetic polymorphisms of the TNF- $\alpha$ and TNF- $\beta$ genes in Malaysian SLE patients," International Journal of Biomedical and Pharmaceutical Sciences, vol. 2, no. 1, pp. 28-33, 2008.

[24] S. N. Yap, M. E. Phipps, M. Manivasagar, S. Y. Tan, and J. J. Bosco, "Human Fc gamma receptor IIA (Fc $\gamma$ RIIA) genotyping and association with systemic lupus erythematosus (SLE) in Chinese and Malays in Malaysia," Lupus, vol. 8, no. 4, pp. 305310, 1999.

[25] T. P. Lau, L. H. Lian, S. M. Puah, C. H. Chew, S. Y. Tan, and K. H. Chua, "Short communication lack of association between CD28 IVS3 + 17T/C SNP and the susceptibility to SLE in the Malaysian population," Asia-Pacific Journal of Molecular Biology and Biotechnology, vol. 16, no. 3, pp. 85-88, 2008.

[26] K. H. Chua, S. M. Puah, C. H. Chew, S. Y. Tan, and L. H. Lian, "Study of the CTLA-4 gene polymorphisms in systemic lupus erythematosus (SLE) samples from Malaysia," Annals of Human Biology, vol. 37, no. 2, pp. 274-281, 2010.

[27] K. H. Chua, T. P. Lau, Z. Y. Tee, S. Y. Tan, and L. H. Liana, "Genetic polymorphisms of the interleukin-1 beta (IL-1 $\beta$ ) -511 and +3954 single nucleotide polymorphisms (SNPs) in Malaysian systemic lupus erythematosus (SLE) patients," Journal of Health Science, vol. 55, no. 4, pp. 657-662, 2009.

[28] T. P. Lau, L. H. Lian, S. Y. Tan, and K. H. Chua, "VNTR polymorphisms of the IF-1RN gene: IL- $1 \mathrm{RN}^{*} 1$ allele and the susceptibility of SLE in the Malaysian population," International Journal of Biomedical and Pharmaceutical Sciences, vol. 2, no. 1, pp. 32-37, 2009.

[29] K. H. Chua, B. P. Kee, S. Y. Tan, and L. H. Lian, "Interleukin6 promoter polymorphisms $(-174 \mathrm{G} / \mathrm{C})$ in Malaysian patients with systemic lupus erythematosus," Brazilian Journal of Medical and Biological Research, vol. 42, no. 6, pp. 551-555, 
2009.

[30] C. S. Hee, S. C. Gun, R. Naidu, S. D. Somnath, and A. K. Radhakrishnan, "The relationship between single nucleotide polymorphisms of the interleukin-10 gene promoter in systemic lupus erythematosus patients in Malaysia: a pilot study," International Journal of Rheumatic Diseases, vol. 11, no. 2, pp. 148-154, 2008.

[31] L. H. Lian, T. P. Lau, A. S. Ching, and K. H. Chua, "ACE gene I/D dimorphism do not play a major role in the susceptibility of Malaysian systemic lupus erythematosus patients," Genetics and Molecular Research 2012 In press.

[32] L. H. Lian, B. P. Kee, H. L. Ng, and K. H. Chua, "Lack of association between RANTES-28, SDF-1 gene polymorphisms and systemic lupus erythematosus in the Malaysian population," Genetics and Molecular Research in 2011 In press.

[33] F. C. Grumet, A. Coukell, J. G. Bodmer, W. F. Bodmer, and H. O. McDevitt, "Histocompatibility (HL-A) antigens associated with systemic lupus erythematosus. A possible genetic predisposition to disease," The New England Journal of Medicine, vol. 285, no. 4, pp. 193-196, 1971.

[34] D. S. Pisetsky, "Systemic lupus erythematosus. A. Epidemiology, pathology and pathogenesis," in Primer on the Rheumatic Disease, J. H. Klippel, Ed., pp. 246-251, Arthritis Foundation, Atlanta, Ga, USA, 11th edition, 1997.

[35] Y. J. Yuan, X. B. Luo, and N. Shen, "Current advances in lupus genetic and genomic studies in Asia," Lupus, vol. 19, no. 12, pp. 1374-1383, 2010.

[36] H. Dunckley, P. A. Gatenby, B. Hawkins, S. Naito, and S. W. Serjeantson, "Deficiency of C4A is a genetic determinant of systemic lupus erythematosus in three ethnic groups," Journal of Immunogenetics, vol. 14, no. 4-5, pp. 209-218, 1987.

[37] M. J. Walport, K. A. Davies, M. Botto, P. J. Lachmann, and M. J. Walport, "C1q and systemic lupus erythematosus," Immunobiology, vol. 199, no. 2, pp. 265-285, 1998.

[38] M. C. Pickering, M. Botto, P. R. Taylor, P. J. Lachmann, and M. J. Walport, "Systemic lupus erythematosus, complement deficiency, and apoptosis," Advances in Immunology, vol. 76, pp. 227-324, 2000.

[39] R. Topaloglu, A. Bakkaloglu, J. H. Slingsby et al., "Molecular basis of hereditary C1q deficiency associated with SLE and IgA nephropathy in a Turkish family," Kidney International, vol. 50, no. 2, pp. 635-642, 1996.

[40] F. Petry, "Molecular basis of hereditary C1q deficiency," Immunobiology, vol. 199, no. 2, pp. 286-294, 1998.

[41] A. G. Wilson, V. S. Giovane, A. I. F. Blakemore, and G. W. Duff, "Single base polymorphism in the human Tumour Necrosis Factor alpha (TNF $\alpha)$ gene detectable by Nco I restriction of PCR product," Human Molecular Genetics, vol. 1, no. 5, p. 353, 1992.

[42] Y. H. Lee, J. B. Harley, and S. K. Nath, "Meta-analysis of TNF$\alpha$ promoter -308 A/G polymorphism and SLE susceptibility," European Journal of Human Genetics, vol. 14, no. 3, pp. 364 371, 2006.

[43] M. P. Bettinotti, K. Hartung, H. Deicher et al., "Polymorphism of the tumor necrosis factor beta gene in systemic lupus erythematosus: TNFB-MHC haplotypes," Immunogenetics, vol. 37, no. 6, pp. 449-454, 1993.

[44] J. Zhang, R. Ai, and F. Chow, "The polymorphisms of HLADR and TNF B loci in northern Chinese Han nationality and susceptibility to systemic lupus erythematosus," Chinese Medical Sciences Journal, vol. 12, no. 2, pp. 107-110, 1997.

[45] F. Takeuchi, K. Nakano, H. Nabeta et al., "Genetic contribution of the tumour necrosis factor (TNF) $\mathrm{B}+252 * 2 / 2$ genotype, but not the TNFa,b microsatellite alleles, to systemic lupus erythematosus in Japanese patients," International Journal of Immunogenetics, vol. 32, no. 3, pp. 173-178, 2005.

[46] Z. K. Indik, J. G. Park, S. Hunter, and A. D. Schreiber, "The molecular dissection of Fc $\gamma$ receptor mediated phagocytosis," Blood, vol. 86, no. 12, pp. 4389-4399, 1995.

[47] F. B. Karassa, T. A. Trikalinos, and J. P. A. Ioannidis, "Role of the Fcy receptor IIa polymorphism in susceptibility to systemic lupus erythematosus and lupus nephritis: a metaanalysis," Arthritis and Rheumatism, vol. 46, no. 6, pp. 15631571, 2002.

[48] S. Y. Tan, "Fc $\gamma$ RIIa polymorphism in systemic lupus erythematosus," Kidney and Blood Pressure Research, vol. 23, no. 2, pp. 138-142, 2000.

[49] D. J. Lenschow, T. L. Walunas, and J. A. Bluestone, "CD28/B7 system of T cell costimulation," Annual Review of Immunology, vol. 14, pp. 233-258, 1996.

[50] Y. H. Lee, J. B. Harley, and S. K. Nath, "CTLA-4 polymorphisms and systemic lupus erythematosus (SLE): a metaanalysis," Human Genetics, vol. 116, no. 5, pp. 361-367, 2005.

[51] M. Linker-Israeli, A. C. Bakke, R. C. Kitridou, S. Gendler, S. Gillis, and D. A. Horwitz, "Defective production of interleukin 1 and interleukin 2 in patients with systemic lupus erythematosus (SLE)," Journal of Immunology, vol. 130, no. 6, pp. 2651-2655, 1983.

[52] C. G. Parks, J. P. Pandey, M. A. Dooley et al., "Genetic polymorphisms in tumor necrosis factor (TNF)- $\alpha$ and TNF- $\beta$ in a population-based study of systemic lupus erythematosus: associations and interaction with the interleukin- $1 \alpha-889 \mathrm{C} / \mathrm{T}$ polymorphism," Human Immunology, vol. 65, no. 6, pp. 622631, 2004.

[53] C. M. Huang, M. C. Wu, J. Y. Wu, and F. J. Tsai, "Lack of association of interleukin- $1 \beta$ gene polymorphisms in Chinese patients with systemic lupus erythematosus," Rheumatology International, vol. 21, no. 5, pp. 173-175, 2002.

[54] J. F. Camargo, P. A. Correa, J. Castiblanco, and J. M. Anaya, "Interleukin- $1 \beta$ polymorphisms in Colombian patients with autoimmune rheumatic diseases," Genes and Immunity, vol. 5, no. 8, pp. 609-614, 2004.

[55] J. K. Tarlow, A. I. F. Blakemore, A. Lennard et al., "Polymorphism in human IL-1 receptor antagonist gene intron 2 is caused by variable numbers of an 86-bp tandem repeat," Human Genetics, vol. 91, no. 4, pp. 403-404, 1993.

[56] A. I. F. Blakemore, J. K. Tarlow, M. J. Cork, C. Gordon, P. Emery, and G. W. Duff, "Interleukin-1 receptor antagonist gene polymorphism as a disease severity factor in systemic lupus erythematosus," Arthritis and Rheumatism, vol. 37, no. 9, pp. 1380-1385, 1994.

[57] H. H. Yu, P. H. Liu, Y. C. Lin et al., "Interleukin 4 and STAT6 gene polymorphisms are associated with systemic lupus erythematosus in Chinese patients," Lupus, vol. 19, no. 10 , pp. 1219-1228, 2010.

[58] M. C. Wu, C. M. Huang, J. J. P. Tsai, H. Y. Chen, and F. J. Tsai, "Polymorphisms of the interleukin-4 gene in Chinese patients with systemic lupus erythematosus in Taiwan," Lupus, vol. 12, no. 1, pp. 21-25, 2003.

[59] C. M. Huang, A. P. Huo, C. H. Tsai, C. L. Chen, and F. J. Tsai, "Lack of association of interleukin-6 and interleukin-8 gene polymorphisms in Chinese patients with systemic lupus erythematosus," Journal of Clinical Laboratory Analysis, vol. 20, no. 6, pp. 255-259, 2006.

[60] E. M. Godarzi, E. K. Sarvestani, E. Aflaki, and Z. Amirghofran, "Interleukin-6 gene polymorphism in Iranian patients with systemic lupus erythematosus," Clinical Rheumatology, vol. 30, no. 2, pp. 179-184, 2011. 
[61] M. J. Santos, D. Fernandes, S. Capela, J. C. da Silva, and J. E. Fonseca, "Interleukin-6 promoter polymorphism -174 G/C is associated with nephritis in Portuguese Caucasian systemic lupus erythematosus patients," Clinical Rheumatology, vol. 30, no. 3, pp. 409-413, 2011.

[62] P. W. Lin, C. M. Huang, C. C. Huang et al., "The association of -627 interleukin-10 promoter polymorphism in Chinese patients with systemic lupus erythematosus," Clinical Rheumatology, vol. 26, no. 3, pp. 298-301, 2007.

[63] A. Sobkowiak, M. Lianeri, M. Wudarski, J. K. Łacki, and P. P. Jagodziński, "Genetic variation in the interleukin-10 gene promoter in Polish patients with systemic lupus erythematosus," Rheumatology International, vol. 29, no. 8, pp. 921-925, 2009.

[64] Y. J. Lin, L. Wan, C. M. Huang et al., "IL-10 and TNFalpha promoter polymorphisms in susceptibility to systemic lupus erythematosus in Taiwan," Clinical and Experimental Rheumatology, vol. 28, no. 3, pp. 318-324, 2010.

[65] R. Pullmann Jr., J. Lukác, M. Skerenová et al., "Association between systemic lupus erythematosus and insertion/deletion polymorphism of the angiotensin converting enzyme (ACE) gene," Clinical and Experimental Rheumatology, vol. 17, no. 5, pp. 593-596, 1999.

[66] K. M. Kaufman, J. Kelly, C. Gray-McGuire et al., "Linkage analysis of angiotensin-converting enzyme (ACE) insertion/deletion polymorphism and systemic lupus erythematosus," Molecular and Cellular Endocrinology, vol. 177, no. 1-2, pp. 81-85, 2001.

[67] H. Sato, Y. Akai, M. Iwano et al., "Association of an insertion polymorphism of angiotensin-converting enzyme gene with the activity of systemic lupus erythematosus," Lupus, vol. 7, no. 8, pp. 530-534, 1998.

[68] G. Lima, E. Soto-Vega, Y. Atisha-Fregoso et al., "MCP-1, RANTES, and SDF-1 polymorphisms in Mexican patients with systemic lupus erythematosus," Human Immunology, vol. 68, no. 12, pp. 980-985, 2007.

[69] D. Q. Ye, S. G. Yang, X. P. Li et al., "Polymorphisms in the promoter region of RANTES in Han Chinese and their relationship with systemic lupus erythematosus," Archives of Dermatological Research, vol. 297, no. 3, pp. 108-113, 2005.

[70] D. Q. Ye, Y. S. Hu, X. P. Li et al., "The correlation between monocyte chemoattractant protein-1 and the arthritis of systemic lupus erythematosus among Chinese," Archives of Dermatological Research, vol. 296, no. 8, pp. 366-371, 2005. 


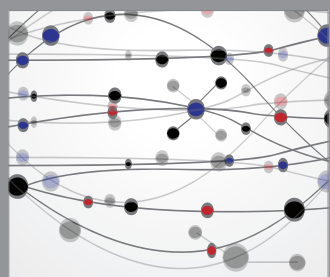

The Scientific World Journal
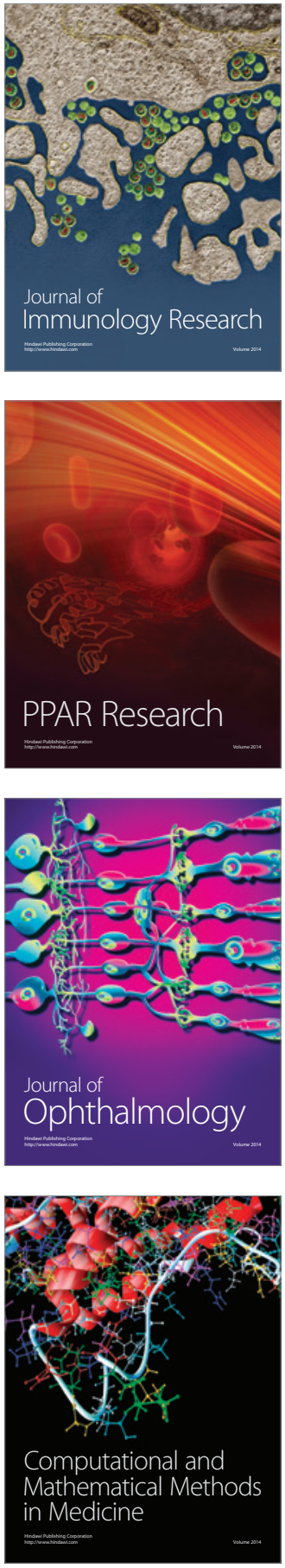

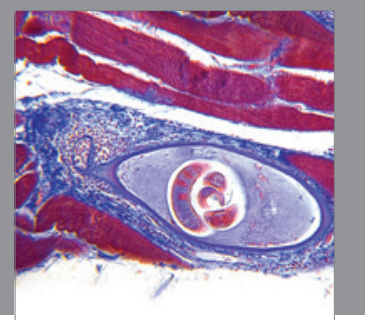

Gastroenterology

Research and Practice
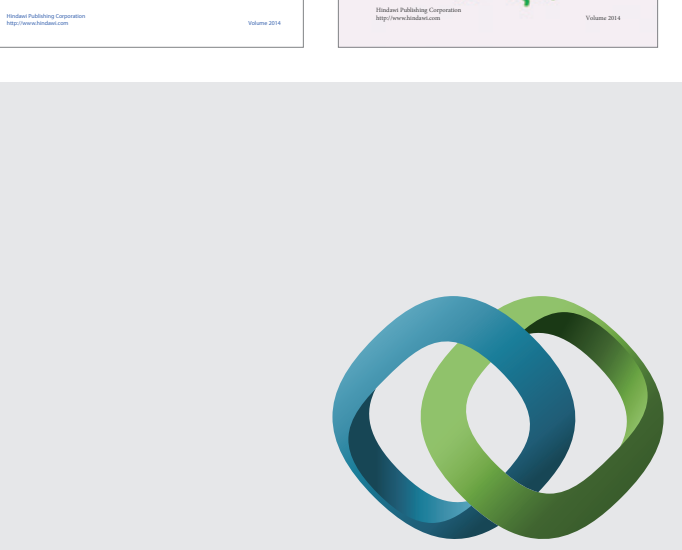

\section{Hindawi}

Submit your manuscripts at

http://www.hindawi.com
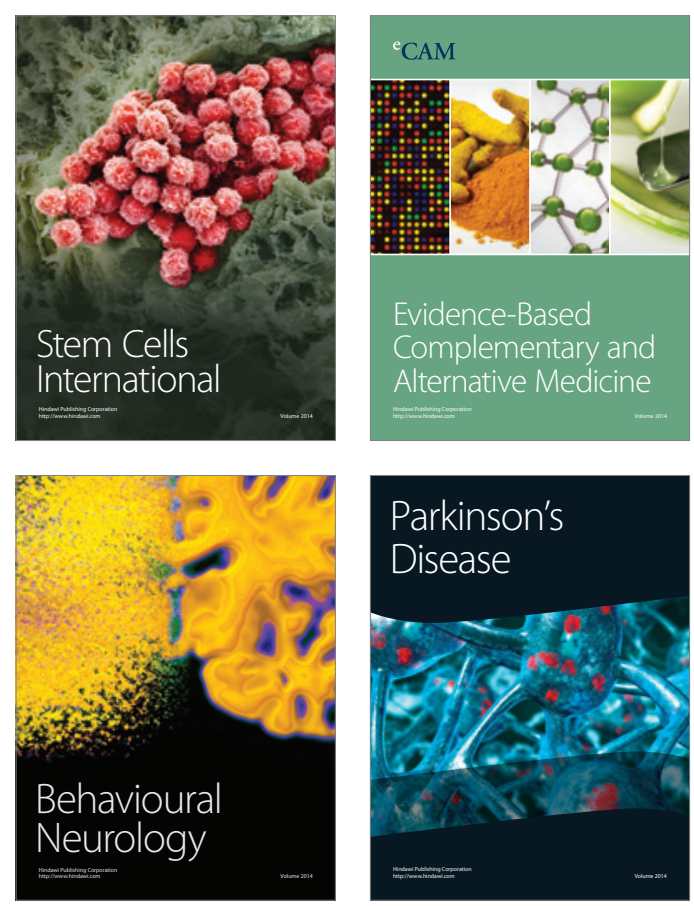

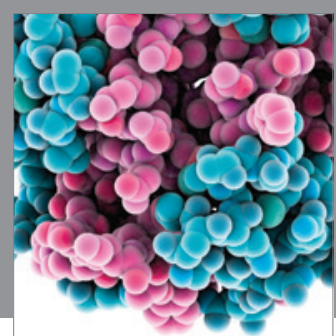

Journal of
Diabetes Research

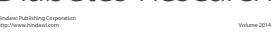

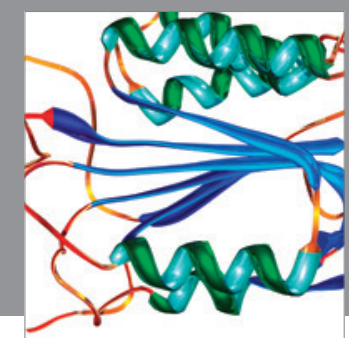

Disease Markers
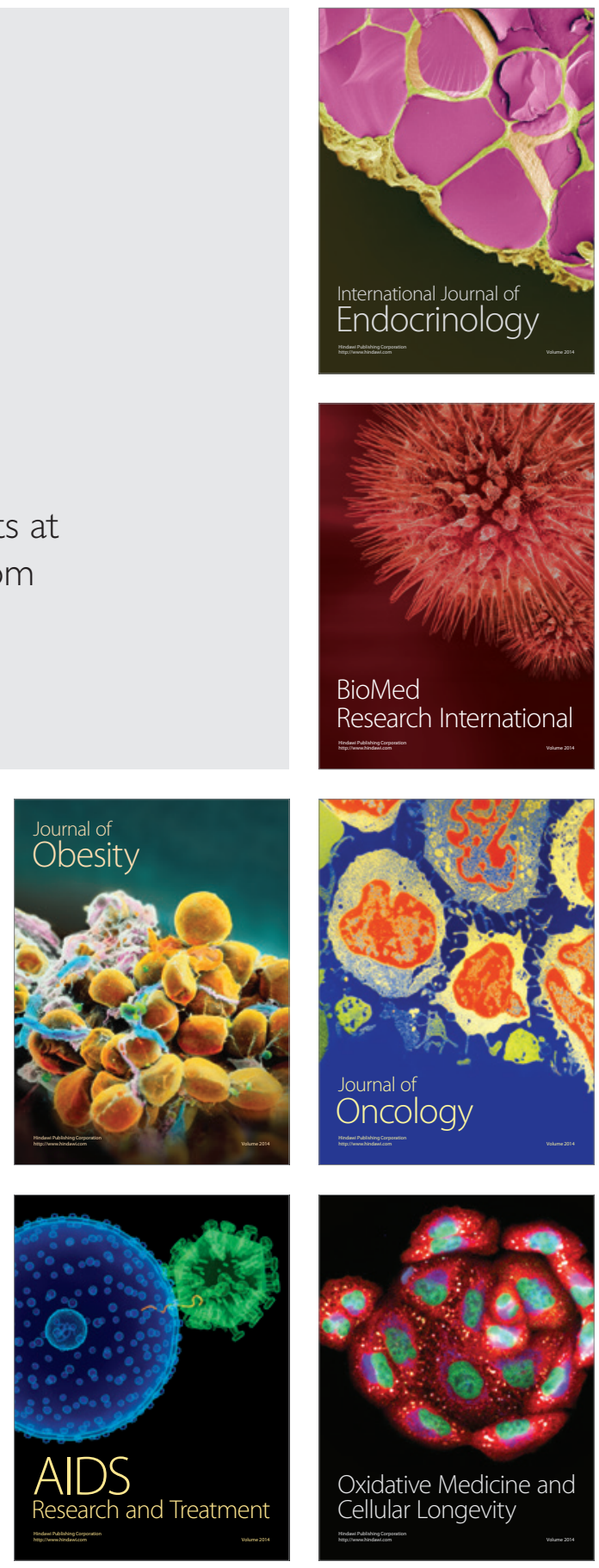